\title{
Hypervitaminosis A during Vertebral Morphogenesis in Larval Japanese Flounder
}

\author{
Jusadi Dedi, ${ }^{* 1}$ Toshio Takeuchi, ${ }^{* 1, \dagger}$ Tadahisa Seikai, ${ }^{* 2}$ \\ Takeshi Watanabe, ${ }^{* 1}$ and Kazumi Hosoya*3 \\ *I Department of Aquatic Biosciences, Tokyo University of Fisheries, Konan, \\ Minato, Tokyo 108, Japan \\ ${ }^{*}$ Fisheries Research Station, Faculty of Agriculture, Kyoto University, \\ Maizuru, Kyoto 625, Japan \\ *3Fish Ecology Section, National Research Institute of Fisheries Science, \\ Komaki, Ueda, Nagano 386, Japan
}

(Received November 7, 1996)

Two experiments were conducted in order to examine the effect of a high amount of vitamin A (VA) given through Artemia on the vertebral development of larval Japanese flounder Paralichthys olivaceus. Ten-day-old flounder larvae were cultured for 30 days. In Experiment I, larvae were fed on Artemia enriched in a 10 -liter medium containing $100 \mathrm{mg}$ VA palmitate ( $1 \mu \mathrm{g}$ VA palmitate $=1$ IU VA), starting from different larval stages until metamorphosis, or at a different rearing period. In Experiment II, critical larval periods (three days) of feeding Artemia enriched in a 10-liter culture medium containing $100 \mathrm{mg}$ VA palmitate on vertebral development were examined.

Enrichment of Artemia with $100 \mathrm{mg}$ VA palmitate in a 10-liter culture medium resulted in 1069 and 918 IU VA per g Artemia (dry basis) in Experiments I and II, respectively. Feeding on Artemia containing these high VA concentrations caused the compression of vertebrae in flounder. This vertebral deformity was found to occur when larvae were exposed to these high dosages of VA during the G stage (during day $25-27$, about $11 \mathrm{~mm}$ of total length) in which notochord segmentation took place. The effect of high dosage of VA was even more distinct in fish receiving VA for a longer period, a high incidence of deformity being accompanied by retardation of growth.

Key words: Vitamin A, Vertebral formation, Vertebral deformity, Flounder, Paralichthys olivaceus, larvae

Previous experiments showed that an excess amount of VA during the larval stages causes bone deformities of flounder Paralichthys olivaceus. A common symptom of the abnormality is the compression of fish vertebrae. ${ }^{1,2)}$ In those experiments, larvae were fed Artemia containing an excess level of VA from the 10th day after hatching until the completion of larval metamorphosis, during which the vertebral column of fish was undergoing development. ${ }^{3)}$ However, in juvenile rainbow trout, ${ }^{4}$ skeletal abnormalities were not the major sign of hypervitaminosis $\mathrm{A}$. This contradictory result was probably due to the difference in size of the fish used. In the case of the juvenile rainbow trout, probably the skeletal frame would have already been formed, and therefore high doses of VA did not have any effect on the fish. The cases of bone deformities reported in flounder seem to be similar to those found in humans in which there was a high prevalence of birth defects related to the cranial neural crest in association with high levels of VA exposure during organ formation. ${ }^{5)}$ Therefore, two experiments were conducted in order to determine the critical larval period when flounder are more prone to vertebral deformity at high doses of VA.

\section{Materials and Methods}

\section{Larval Rearing}

Two experiments were conducted using 10-day-old flounder larvae Paralichthys olivaceus at the Fisheries Research Station, Faculty of Agriculture, Kyoto University, Maizuru, Kyoto. The flounder eggs for Experiment I were obtained from the Miyazu station of Japan Sea Farming Association. Those used in Experiment II were from the hatchery of Yamagataya Suisan Co. Ltd., Hyogo Prefecture. They were hatched in a 500 liter tank, and kept for 10 days at $18.3^{\circ} \mathrm{C}$ and $19.2^{\circ} \mathrm{C}$ in Experiments I and II, respectively, before the start of the feeding experiment.

The experiments were conducted in a 100-liter transparent polycarbonate tanks, each holding 1000 larvae. The initial total length of the larvae was $5.7 \pm 0.47 \mathrm{~mm}$ in Experiment $I$ and $5.6 \pm 0.49 \mathrm{~mm}$ in Experiment II. During the feeding period, the rearing tanks received aeration at a flow of $75-100 \mathrm{~cm}^{3} / \mathrm{min}$. The water flow was about 200 $300 \mathrm{ml} / \mathrm{min}$. Water temperature in each tank was maintained at $18.2 \pm 0.4^{\circ} \mathrm{C}$ in Experiment $\mathrm{I}$ and $18.6 \pm 0.4^{\circ} \mathrm{C}$ in Experiment II.

† Corresponding author: Tel/Fax. (81-3) 5463-545. E-mail.take@tokyo-u-fish.ac.jp. 


\section{Feed and Feeding}

The feeding schedule employed for flounder larvae during the rearing period is summarized in Figs. 1 and 2. Rotifers Brachionus plicatilis were added to all the fish-culture tanks at a density of $5 \mathrm{ind} . / \mathrm{m} /$ from the 3 rd day after hatching till day 20 . In both experiments, rotifers were enriched with $25 \mathrm{~g}$ of Aquaran (Takeda Kagaku Shiryo Co. Ltd.), or $5 \mathrm{ml}$ DHA-38G containing $10.6 \%$ eicosapentaenoic acid (EPA) and 35.8\% docosahexaenoic acid (DHA) (Nippon Chemical Feed Co. Ltd.) in a 100-liter culture medium (180 ind. rotifer $/ \mathrm{ml}$ ) for more than $16 \mathrm{~h}$ at $17^{\circ} \mathrm{C}$.

Artemia nauplii hatched during $48 \mathrm{~h}$ or $24 \mathrm{~h}$ incubations were enriched with one of the varieties of emulsified solution for more than $18 \mathrm{~h}$ at a density of $100-150$ ind. $/ \mathrm{ml}$ medium at a water temperature of $20^{\circ} \mathrm{C}$. They were then introduced to the experimental tanks twice a day at 08:00 and 13:00 from day 11 to day 39 .

In Experiment I, Tien-tsin or Utah strain Artemia

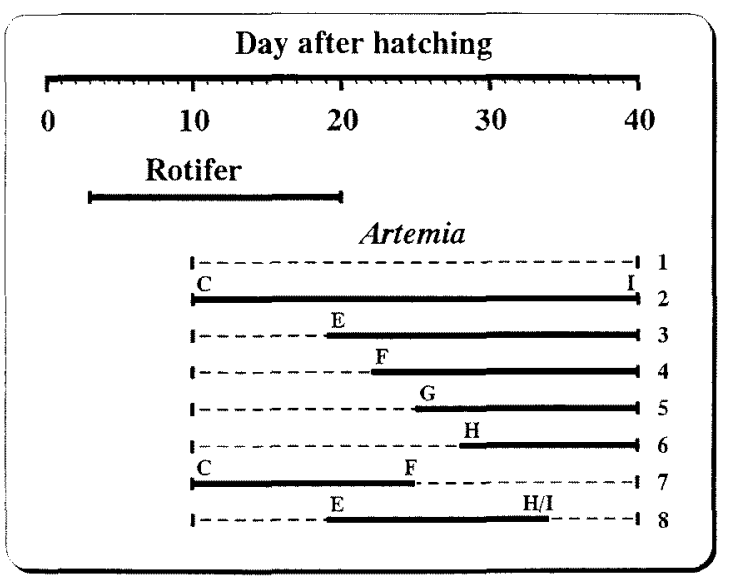

Fig. 1. Feeding schedule applied to larval flounder during rearing period in Experiment I.

- Artemia enriched with n-3HUFA; - Artemia enriched with n-3HUFA and VA.

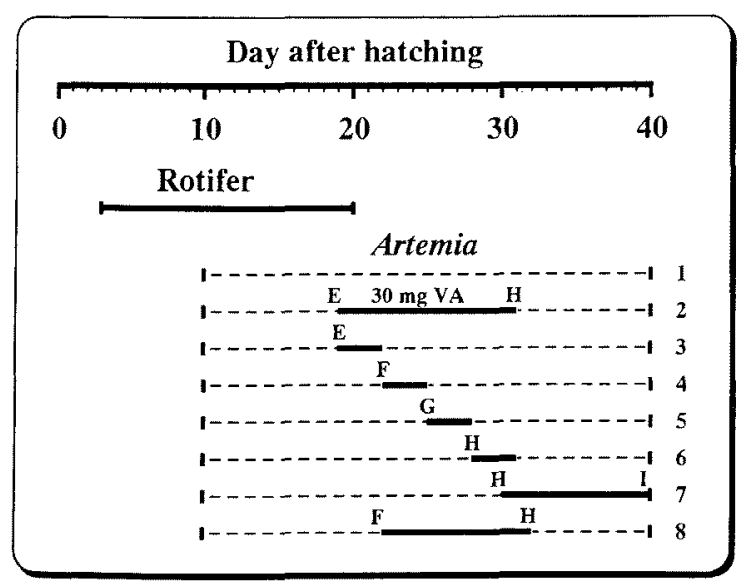

Fig. 2. Feeding schedule applied to larval flounder during rearing period in Experiment II.

-...- Artemia enriched with n-3HUFA; _- Artemia enriched with n-3HUFA and VA. nauplii were prepared for eight different treatments by the direct method ${ }^{6}$ Since two lots of Tien-tsin strain cysts had an extremely low hatchability, Utah strain was used from day 33 till day 39. As a control treatment, Artemia nauplii were enriched with $0.5 \mathrm{~g}$ Ester-85 (methyl esters n-3HUFA containing $30.1 \%$ EPA and $46.3 \%$ DHA; Nippon Chemical Feed Co. Ltd.). In order to examine the effect of a high amount of VA on the vertebral development, Artemia nauplii were enriched with $100 \mathrm{mg}$ VA palmitate $(1 \mu \mathrm{g}$ VA palmitate=1 IU VA; Nippon Roche K.K.) which were emulsified in $0.5 \mathrm{~g}$ Ester-85.

In Experiment II, Utah strain Artemia nauplii were enriched with the same method as that in Experiment $I$ and prepared for eight different treatments. As a control treatment, Artemia nauplii were enriched with $0.5 \mathrm{~g}$ ethyl esters of a mixture of oils (ratio $1: 1$ ) of $71.1 \%$ n-3HUFA and $89.9 \%$ DHA (Nippon Chemical Feed Co. Ltd. and Nippon Suisan Kaisha Ltd., respectively), containing $11.3 \%$ EPA and $66.8 \%$ DHA. In a manner similar to Experiment I, Artemia were enriched with either 30 or $100 \mathrm{mg}$ VA palmitate which were emulsified in $0.5 \mathrm{~g}$ ethyl esters.

Each enrichment material in Experiments I and II was homogenized with $0.1 \mathrm{~g}$ of raw egg yolk and $100 \mathrm{~m} /$ water by a mixer for $2 \mathrm{~min}$, in order to make a stable homogeneous emulsion. Then, the mixture was poured into a 10-liter Artemia culture medium with aeration.

In Experiment I (Fig. 1), Artemia enriched with $100 \mathrm{mg}$ VA palmitate were offered to the larvae of different larval stages, or at a different rearing period. In treatment 1, larvae were fed on Artemia enriched with $0.5 \mathrm{~g}$ Ester-85 without VA from day 10 till day 39. In treatments 2 to 6 , larvae were fed on Artemia enriched with $100 \mathrm{mg}$ VA palmitate either from day $10,19,22,25$, or $28(C, E, F, G$, $\mathrm{H}$ of larval stages) ${ }^{7}$ till day 39 (I stage). In treatment 7, larvae were fed on Artemia enriched with $100 \mathrm{mg}$ VA palmitate during day $10-25$ (in the period of $C, D, E$ and the end of $\mathrm{F}$ stages). In treatment 8 , larvae were fed on $\mathrm{Ar}$ temia enriched with $100 \mathrm{mg}$ VA palmitate during day 1934 (during E, F, G, and the of $\mathbf{H}$ or early I stages).

In Experiment II (Fig. 2), larvae were fed on Artemia enriched with either 30 or $100 \mathrm{mg}$ VA for a short period during each larval stage to reveal the critical period of larval development. In treatment 1, larvae were fed on Artemia enriched with $0.5 \mathrm{~g}$ ethyl ester from day 10 till day 39 . In treatment 2, larvae were fed on Artemia enriched with 30 mg VA palmitate from day 19 till day 31 . In treatments 3 to 6, larvae were fed on Artemia enriched with $100 \mathrm{mg}$ VA palmitate for 3 days, from days $19,22,25$, or 28 , respectively. In treatments 7 and 8 , larvae were fed on Artemia enriched with $100 \mathrm{mg}$ VA palmitate for an interval of 10 days at different stages.

\section{Analytical Procedure}

Biological analyses were carried out on fish at the end of the rearing experiments (day 40). After being anesthetized with 3-aminobenzoic acid ethyl esters (MS-222), the total length and individual body weight were recorded from 50 and 250 fishes in Experiment $\mathrm{I}$, and 50 and the remaining fish in Experiment II. The individual body weight of the fish was estimated by dividing the total biomass by the number of fish. Duncan's multiple test was applied to compare the means of total length when the significance 
$(p<0.05)$ of factor was detected by ANOVA. ${ }^{8)}$

Vertebral column development of flounder larvae was observed during each larval stage using 30 or 100 specimens after being preserved in a $10 \%$ buffered neutral formalin solution. The skeletal structure was observed using Alizarin red staining. ${ }^{9,10)}$ Chemical analyses such as fatty acid composition, lipid classes, and VA contents were carried out on 40-day-old fish, rotifers and Artemia.

During the feeding period, rotifers and Artemia nauplii of each treatment were collected everyday. Artemia nauplii were divided into two or three groups in Experiments I and II, respectively, and then harvested by centrifuging at $8,000 \mathrm{rpm}$ for $10 \mathrm{~min}$ for analysis. Lipids were extracted from both live food and fish with a chloroform and methanol mixture $(2: 1)$ following the Folch method. ${ }^{11)}$ Crude lipids of fish were diluted in hexane, and VA content was analyzed using HPLC with a spectrofluorophotometer RF 5000 detector (Shimadzu Corp.). Crude lipid from live food was saponified with $50 \%$ ethanol-KOH solution and $50 \mathrm{mg}$ pyrogallol, and the extracted unsaponifiables were used for VA analysis. ${ }^{12)}$ For DHA analysis, saponifiables (free fatty acids) were prepared to methylesters with $7 \%$ boron trifluoride in methanol solution $\left(\mathrm{BF}_{3}\right.$-methanol), and $\mathrm{DHA}$ content was determined by using gas liquid chromatograph (GLC). ${ }^{13)}$ Sep-Pak Silica Cartridges (Sep-Pak, Water) were used for the separation of neutral and polar lipids, with chloroform and methanol as a solvent for both lipid classes, respectively. ${ }^{14)}$ All chemical analysis data is presented as a dry matter basis.

\section{Results}

\section{Experiment I: A High Amount VA Intake at Different Feeding Intervals}

The essential nutrient content of live food used for flounder larvae is presented in Table 1 . The essensial fatty acid content in the live foods used in this experiment was high enough to fulfill the requirement of larval flounder, ${ }^{15}$ ) especially with high content of polar lipid in Artemia. Rotifers and Artemia used for the control treatment contained a small amount of VA. On the other hand, Artemia enriched with $100 \mathrm{mg}$ VA palmitate contained a fairly high amount of VA. This big difference between the control and VA enriched Artemia would be responsible for feed performances such as growth and vertebral development.

The results of feeding flounder larvae on Artemia enriched with $100 \mathrm{mg}$ VA palmitate at different intervals during the feeding period are presented in Table 2 . At the end of the feeding trial, the group of fish with the control treatment had the longest total length and the heaviest body weight. This result suggested that feeding Artemia with the high amount of VA to larvae at all stages could reduce the growth of fish. The effect of VA on the growth of fish was more distinct in those groups fed the vitamin for a longer period.

Table 2 shows that the occurrence of vertebral deformity was low in fish with the control treatment (treatment no. 1). The incidence of this abnormality increased in fish fed Artemia enriched with a high amount of VA. Except for fish treated with VA starting from the $\mathrm{H}$ stage (treatment 6), all groups of fish treated with VA had the compressed vertebrae, a characteristic of hypervitaminosis induced by VA. ${ }^{2)}$ The highest frequency of vertebral deformity of fish in treatment 6 was found in the central fusion between vertebra no. 37 and terminal urostyle (Fig. 3). The occurrence frequency of the abnormality is inversely related to the growth of fish.

The vertebral column development of flounder in each larval stage, in which the provisional effect of a high amount of VA was beginning, are presented in Fig. 4. The red color of alizarin red staining indicated the ossification of the vertebral column. Until larvae reached the early $G$ stage, the transparent membrane of the notochord was still visible. In the early $G$ stage, the urostyle region started to ossify. On day 28 , in the early $\mathbf{H}$ stage, the notochord became separated transversely by vertebrae, suggesting that notochord segmentation took place during the $G$ stage. Irrespective of the various feeding intervals for the intake of VA, the vertebral column patterns of fish in all treatments were the same until the larvae reached the early $\mathrm{H}$ stage. As reported by Dedi et al. ${ }^{2)}$ the compressed vertebrae of fish due to the side effect of high doses of VA was distinguished from the control group after reaching the 40 day-old stage.

On day 40, although fish in treatments 5, 7 and 8 had already fed Artemia enriched with the high amount of VA during the same interval, the VA contents of fish in treatments 7 and 8 were low compared to the fish in treatment 5 (Table 3). After feeding Artemia enriched with a high dose
Table 1. Certain fatty acids in the total lipids, lipid classes and vitamin A contents (dry basis) of live foods for flounder larvae in Experiment I

\begin{tabular}{lccc}
\hline & & \multicolumn{2}{c}{ Enriched Artemia } \\
\cline { 4 - 4 } & Rotifers & $0 \mathrm{mg}$ VA & $100 \mathrm{mg}$ VA \\
\hline Fatty acid $(\mathrm{g} / 100 \mathrm{~g})$ & & & \\
EPA & 3.4 & 3.5 & 3.0 \\
DHA & 3.1 & 1.9 & 1.1 \\
n-3HUFA & 8.1 & 5.8 & 4.4 \\
Lipid class (g/100g) & & & \\
Total lipid & 20.3 & 24.4 & 23.1 \\
Neutral lipid & 16.7 & 16.1 & 15.9 \\
Polar lipid & 3.6 & 8.3 & 7.2 \\
Vitamin A (IU/g) & 2.2 & 4.0 & 1069.2 \\
\hline
\end{tabular}

Table 2. Effects of feeding Artemia enriched with $100 \mathrm{mg}$ vitamin A palmitate at different periods during larval stages on growth, survival and vertebral development of flounder in Experiment I

\begin{tabular}{llccc}
\hline \multicolumn{1}{c}{ Treatment } & $\begin{array}{c}\text { Total } \\
\text { length } \\
(\mathrm{mm})\end{array}$ & $\begin{array}{c}\text { Body } \\
\text { weight } \\
(\mathrm{mg})\end{array}$ & $\begin{array}{c}\text { Survival } \\
\text { rate } \\
(\%)\end{array}$ & $\begin{array}{c}\text { Vertebral } \\
\text { deformity } \\
(\%)\end{array}$ \\
\hline 1. Control & $22.1 \pm 3.2^{\text {at }}$ & 85.4 & 85.9 & 18.0 \\
2. 100 VA: C $\sim$ I & $16.8 \pm 2.2^{\mathrm{d}}$ & 52.7 & 87.8 & 100.0 \\
3. 100 VA: $\mathrm{E} \sim 1$ & $17.5 \pm 2.3^{\mathrm{d}}$ & 57.0 & 84.5 & 100.0 \\
4. 100 VA: $\mathrm{F} \sim \mathrm{I}$ & $17.7 \pm 2.3^{\mathrm{d}}$ & 54.8 & 85.2 & 100.0 \\
5. 100 VA: $\mathrm{G} \sim \mathrm{I}$ & $20.4 \pm 2.6^{\mathrm{b}}$ & 66.1 & 80.2 & 96.0 \\
6. 100 VA: $\mathrm{H} \sim \mathrm{I}$ & $20.5 \pm 2.5^{\mathrm{b}}$ & 78.6 & 80.3 & 40.0 \\
7. 100 VA: $\mathrm{C}, \mathrm{D}, \mathrm{E}, \mathrm{F}$ & $18.9 \pm 3.4^{\mathrm{c}}$ & 72.5 & 82.6 & 68.0 \\
8. 100 VA: E, F, G, H & $17.8 \pm 2.3^{\text {cd }}$ & 56.3 & 83.4 & 96.0 \\
\hline
\end{tabular}




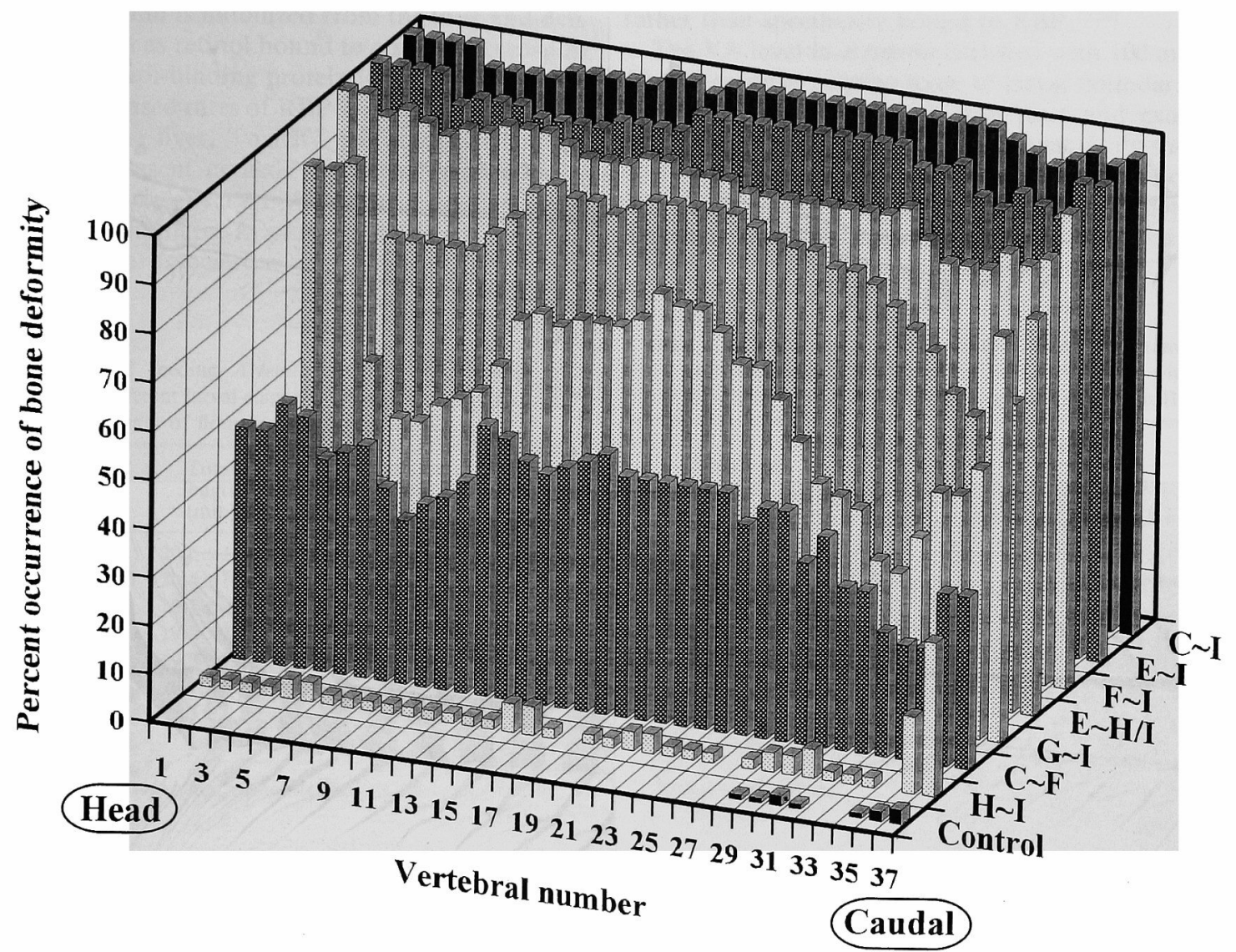

Fig. 3. The occurrence frequency of vertebral deformity in flounder fed Artemia enriched with $100 \mathrm{mg}$ VA palmitate at different intervals during the larval stages in Experiment I.

of VA, the fish in treatment 7 were fed on enriched Artemia containing no VA for 15 days. Possibly, during the last 15 days, excess VA that had already accumulated was metabolized and secreted so that the VA content in the body of fish became low, similar to that in the control fish. On the other hand, VA content in the body of fish in treatment 8 was twofold higher than the control fish. In the case of treatment 8, after the feeding of Artemia enriched with a high dose of VA, the fish were fed on enriched Artemia containing no VA for only 6 days. It seems that during the last 6 days, excess VA that had already accumulated was not secreted completely and still remained at the end of experiment.

\section{Experiment II: Critical Period of VA Intake for Vertebral Development}

The nutrient content of food used during the experimental period is presented in Table 4. Similar to the result in Experiment I, the essential fatty acid contents in live foods was enough to fulfill the requirement of larval flounder. The VA content of Artemia used in each treatment was increased as the VA content in the oil used for enrichment elevated, and Artemia enriched with $100 \mathrm{mg}$ VA palmitate contained a very high amount of VA.

After complete metamorphosis (40-day-old), there was a variation in the average fish size between each treatment $(\mathrm{T}$ able 5). The size of fish are related to the VA contents.
Fish fed Artemia enriched with $100 \mathrm{mg}$ VA during the E larval stage (treatment 3 ) reached the same size as those in the control treatment (treatment 1). A similar growth rate with the control treatment was also obtained by fish fed $\mathrm{Ar}$ temia enriched with $30 \mathrm{mg}$ VA palmitate (treatment 2). Feeding on Artemia enriched with $100 \mathrm{mg}$ VA palmitate after day 22 (the F larval stage) resulted in reduced growth.

The occurrence of vertebral deformity of fish varied from 12 to $100 \%$ among treatments (Table 5). A high occurrence of vertebral deformity was found in the group of fish treated with $100 \mathrm{mg}$ VA palmitate during the $\mathrm{G}$ stage (treatment 5) and in the periods of the F, G and $\mathrm{H}$ stages (treatment 8) (Fig. 5). The group of fish in treatment 8 was fed with a high amount of VA for a longer period than those in treatment 5, so that the occurrence frequency of vertebral deformity was higher in the former than the latter. Moreover, it was also found that fish with compressed vertebrae were detected only in these treatments. Therefore, even during a short feeding period of 3 days (25th27 th days after hatching) at the G larval stage, the application of a high amount of VA exerted ill effects on vertebral development.

Although fish in treatments 7 and 8 had already been treated with the high amount of VA in the same interval, the VA content of fish in treatment 8 was lower. After the feeding of Artemia enriched with a high dose of VA, the fish in treatment 8 were fed on enriched Artemia contain- 


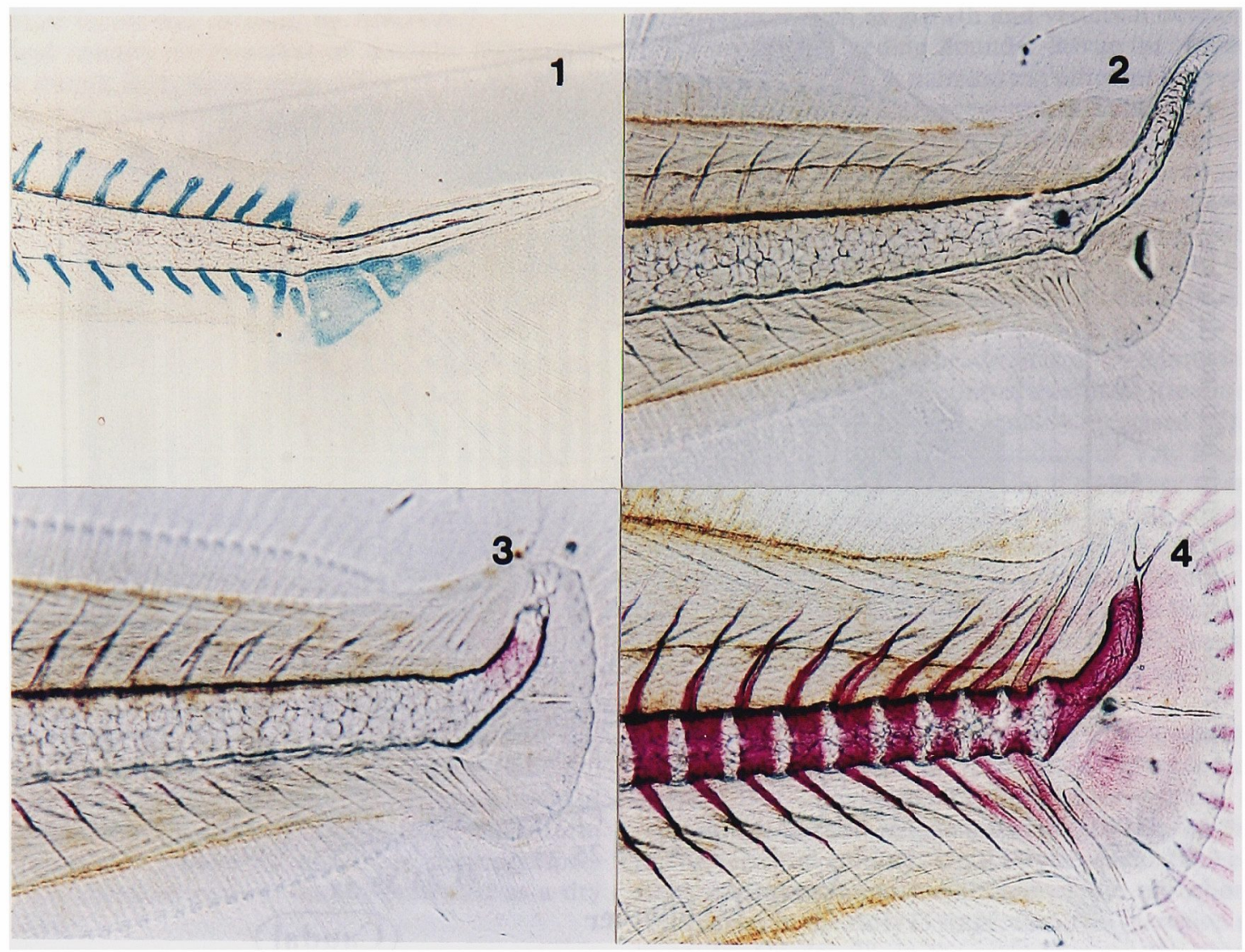

Fig. 4. The vertebral column (notochord) development of flounder larval during the rearing period. (1) 19-day-old fiounder (E stage) with total length of $4.8 \sim 6.5 \mathrm{~mm}$; (2) 22-day-old flounder (F stage) with total length of 9.2 9.4 mm; (3) 25-day-old flounder (G stage) with total length of $10.8 \sim 11.9 \mathrm{~mm}$; (4) 28-day-old flounder (H stage) with total length of $12.7 \sim 13.0 \mathrm{~mm}$.

Table 3. Certain fatty acids in the total lipids and vitamin A contents (dry basis) of flounder fed Artemia enriched with $100 \mathrm{mg}$ vitamin A palmitate at different periods during larval stage in Experiment I

\begin{tabular}{|c|c|c|c|c|c|}
\hline \multirow{2}{*}{ Treatment } & \multirow{2}{*}{$\begin{array}{l}\text { Lipid } \\
(\%)\end{array}$} & \multicolumn{3}{|c|}{ Fatty acid $(\mathrm{g} / 100 \mathrm{~g})$} & \multirow{2}{*}{$\begin{array}{l}\text { Vitamin } A \\
(\mathrm{IU} / \mathrm{g})\end{array}$} \\
\hline & & EPA & DHA & $\mathrm{n}$-3HUFA & \\
\hline Initial fish ${ }^{1}$ & 20.9 & 2.3 & 3.3 & 7.8 & 13.4 \\
\hline 1. Control & 18.7 & 2.2 & 1.7 & 4.6 & 20.6 \\
\hline 2. $100 \mathrm{VA}: \mathrm{C} \sim \mathrm{I}$ & 17.7 & 2.0 & 1.3 & 4.0 & 131.0 \\
\hline 3. 100 VA: $\mathrm{E} \sim \mathrm{I}$ & 18.6 & 2.1 & 1.3 & 4.1 & 112.7 \\
\hline 4. 100 VA: $F \sim I$ & 18.3 & 1.5 & 0.7 & 2.7 & 123.8 \\
\hline 5. 100 VA: $G \sim I$ & 18.5 & 1.7 & 0.7 & 2.9 & 124.6 \\
\hline 6. 100 VA: $\mathrm{H} \sim \mathrm{I}$ & 19.5 & 1.6 & 0.8 & 3.0 & 127.9 \\
\hline 7. 100 VA: $C, D, E, F$ & 18.4 & 1.9 & 1.1 & 3.6 & 18.9 \\
\hline 8. 100 VA: $E, F, G, H$ & 18.6 & 2.1 & 1.4 & 4.3 & 41.2 \\
\hline
\end{tabular}

110 days after hatching.

ing no VA for 9 days (Table 6). Similar to Experiment I, excess VA that had already accumulated was metabolized and secreted so that the VA content in the body of fish decreased.

\section{Discussion}

The occurrence of vertebral deformity observed in Ex-
Table 4. Certain fatty acids in the total lipids, lipid classes and vitamin A contents (dry basis) of live foods for flounder larvae in Experiment II

\begin{tabular}{lrrrr}
\hline & & \multicolumn{4}{c}{ Artemia, enriched with VA (mg) } \\
\cline { 3 - 5 } & Rotifer & 0 & 30 & 100 \\
\hline Fatty acid (g/100 g) & & & & \\
$\quad$ EPA & 2.8 & 2.2 & 2.1 & 2.1 \\
DHA & 2.1 & 1.7 & 1.6 & 1.7 \\
n-3HUFA & 5.9 & 4.4 & 4.2 & 4.4 \\
Lipid class (g/100 g) & & & & \\
$\quad$ Total lipid & 22.8 & 29.9 & 29.9 & 30.7 \\
$\quad$ Neutral lipid & 17.7 & 21.4 & 21.1 & 22.5 \\
$\quad$ Polar lipid & 5.1 & 8.5 & 8.8 & 8.2 \\
Vitamin A (IU/g) & 3.8 & 6.5 & 69.6 & 918.4 \\
\hline
\end{tabular}

periments I and II clearly demonstrated that a high dosage of VA through Artemia exert an ill effect on the larval development of Japanese flounder. On day 28 , in the $\mathrm{H}$ stage, the vertebral column of fish was visible (Fig. 4), suggesting that the notochord segmentation of fish took place during the $G$ stage of larvae (from day 25 till day 27). Namely, a high concentration of VA in the body of fish during the period of notochord segmentation adversely affected their development.

It is well known that VA is stored primarily in the 
liver. ${ }^{16,17)}$ The vitamin is mobilized from the liver and delivered to the tissues as retinol bound to a specific transport protein called retinol-binding protein (RBP). ${ }^{18)}$ The excess of VA led to decreased rates of RBP synthesis in, and RBP secretion from, the liver. Toxicity occurs only when the amount of VA present exceeds the capacity of RBP to bind to it. The toxic effect of VA occurs when excessive amounts of VA circulates in plasma and is presented to cell membranes in association with plasma lipoprotein,

Table 5. Effects of feeding Artemia enriched with vitamin A palmitate at different larval stages on growth, survival and vertebral development of flounder in Experiment II

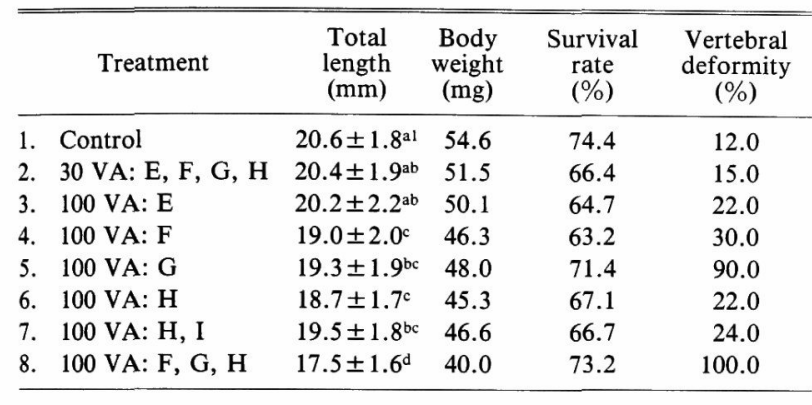

Values with the same superscript are not significantly different $(p<0.05)$. rather than specifically bound to RBP. ${ }^{19,20)}$

The VA level in Artemia enriched with $100 \mathrm{mg}$ VA in a 10-liter medium seemed toxic to larval flounder. This VA concentration might be an over dose and exceeded the RBP capacity to bind VA. The present study showed that when this enriched Artemia was fed to larvae before or during vertebral formation, vertebral deformity could occur. The toxic effect of a high dosage of VA occurred when this

Table 6. Certain fatty acids in the total lipids and vitamin A contents (dry basis) of flounder fed Artemia enriched with vitamin A palmitate at different larval stage in Experiment II

\begin{tabular}{|c|c|c|c|c|c|}
\hline \multirow{2}{*}{ Treatment } & \multirow{2}{*}{$\begin{array}{c}\text { Lipid } \\
(\%)\end{array}$} & \multicolumn{3}{|c|}{ Fatty acid $(\mathrm{g} / 100 \mathrm{~g})$} & \multirow{2}{*}{$\underset{(I U / g)}{\text { Vitamin }} A$} \\
\hline & & EPA & DHA & n-3HUFA & \\
\hline Initial fish ${ }^{1}$ & 16.4 & 1.3 & 1.2 & 3.6 & 3.0 \\
\hline 1. Control & 20.2 & 1.6 & 1.7 & 4.0 & 14.6 \\
\hline 2. 30 VA: $\mathrm{E}, \mathrm{F}, \mathrm{G}, \mathrm{H}$ & 21.1 & 1.7 & 1.4 & 3.8 & 15.5 \\
\hline 3. $100 \mathrm{VA}: \mathrm{E}$ & 20.2 & 1.7 & 1.6 & 4.0 & 12.5 \\
\hline 4. 100 VA: $F$ & 20.5 & 1.8 & 1.4 & 3.9 & 13.2 \\
\hline 5. $100 \mathrm{VA}: \mathrm{G}$ & 19.8 & 1.7 & 1.6 & 4.0 & 16.5 \\
\hline 6. $100 \mathrm{VA}: \mathrm{H}$ & 19.2 & 1.6 & 1.3 & 3.5 & 18.3 \\
\hline 7. $100 \mathrm{VA}: \mathrm{H}, \mathrm{I}$ & 19.2 & 1.5 & 1.4 & 3.6 & 120.9 \\
\hline 8. 100 VA: $F, G, H$ & 19.9 & 1.6 & 1.4 & 3.7 & 24.6 \\
\hline
\end{tabular}

110 days after hatching.

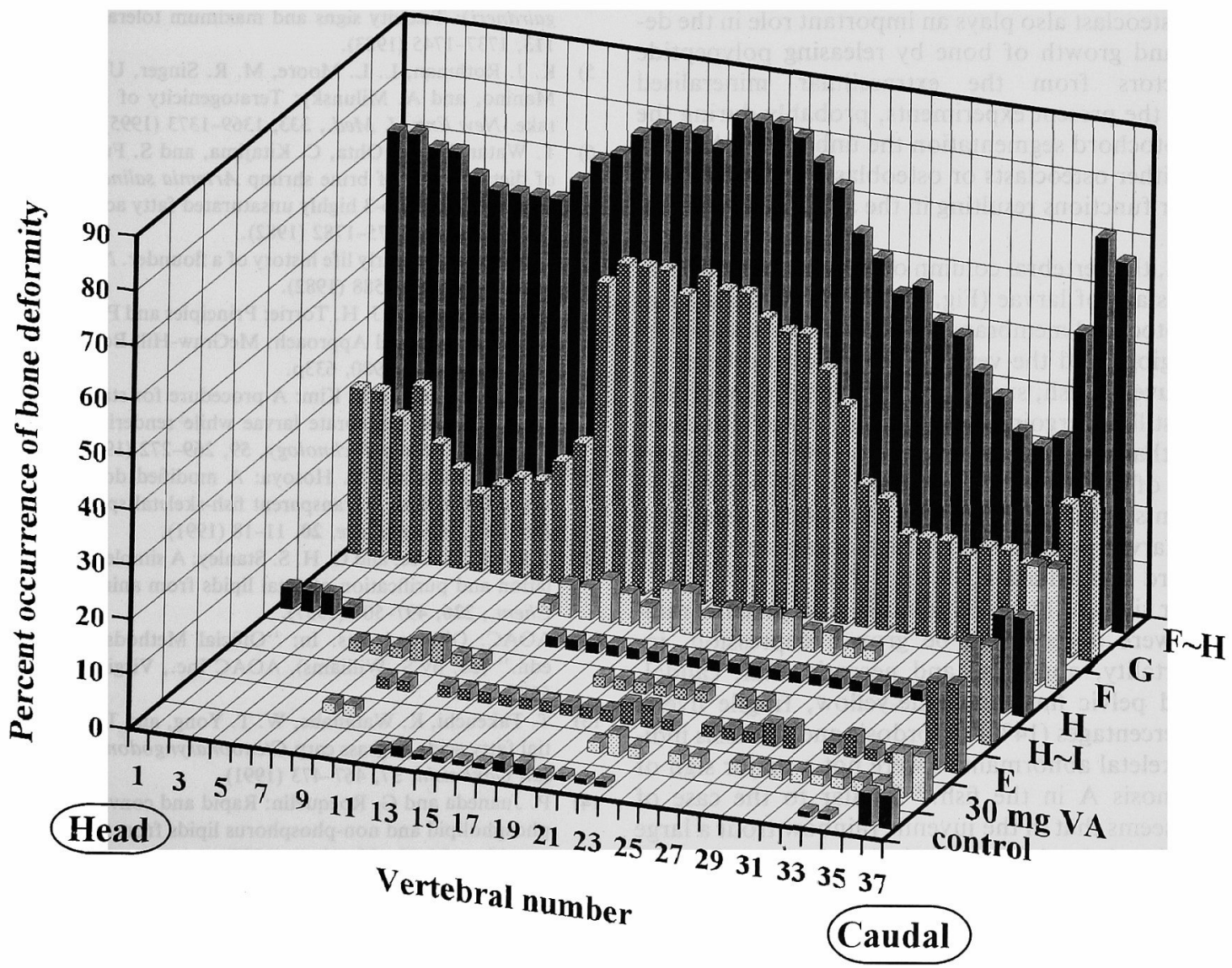

Fig. 5. The occurrence frequency of vertebral deformity in flounder fed Artemia enriched with $100 \mathrm{mg}$ VA palmitate at different larval stages in Experimental II. 
level of VA was given for a long period prior to vertebral formation (i.e., treatment 7 of Experiment I). On the other hand, in a short feeding period (i.e., treatment 4 of Experiment II) the application of a high amount of VA before vertebral formation did not give any toxic effect on its vertebral morphology. It seems that in a long feeding period (Treatment 7 of Experiment I) VA excessively accumulated in the liver and was toxic. Although high doses of VA given were terminated prior to the vertebral formation (day 24 or at the end of the F stage), deformation still occurred. A possible explanation is that the stored VA still remained in the fish during vertebral formation. Therefore, even though feeding with a high amount of VA was discontinued, the concentration of VA in the liver was sufficiently high enough, exceeding the capacity of RBP to bind to it. Then the excess amount of VA circulated in association with plasma lipoproteins, and in its free form interacted with the membrane of the notochord till segmented to form the vertebrae. Consequently, as observed in treatment 5 of Experiment II, a toxic effect also occurred when Artemia with a high level of VA were given to larvae during the period of notochord segmentation (days 25-27). Larger excess of VA dosage during vertebral formation resulted in a higher frequency of vertebral deformity.

Excess VA affects the activity of either osteoclasts or osteoblasts ${ }^{21)}$ which are principal cells involved in bone formation. The osteoblast produces the matrix, which in a well regulated process becomes calcified to form the partially calcified osteoid and ultimately the fully mineralised bone. The osteoclast also plays an important role in the development and growth of bone by releasing polypeptide growth factors from the extracellular mineralised matrix. ${ }^{22)}$ In the present experiments, probably during the period of notochord segmentation the unbound VA interfered with either osteoclasts or osteoblasts and adveresely affected their functions resulting in the abnormal vertebral morphology.

On day 28 , the vertebral column of fish became visible in the early $\mathrm{H}$ stage of larvae (Fig. 4). However, during this stage, the notochord membrane was still visible in the intervertebral regions and the vertebral shape also differed to that in the juvenile fish, suggesting that vertebral morphogenesis was still undergoing development. It was also clearly observed that overdoses of VA had no effect on the vertebral shape of fish after the period of day 28 (treatment 6 in Experiments I and II). Therefore, the toxicity seemed to occur when larvae were exposed to high dosages of VA during notochord segmentation, but not after.

The major signs of hypervitaminosis A in juvenile rainbow trout were observed to be growth depression, increased mortality, abnormal and necrotic anal, caudal, pectoral and pelvic fins, and pale-yellow, fragile livers. The small percentages ( $14 \%$ ) of lordosis and scoliosis indicated that skeletal abnormalities were not a major sign of hypervitaminosis $\mathrm{A}$ in the fish. ${ }^{4}$ ) Similar to the case of flounder, it seems that in the juvenile rainbow trout a large portion of the skeletal frame had already been formed, and therefore a high intake of VA did not have any effect on its vertebrae. Thus, the results of the present experiments also illustrated as why bone deformity was not a major sign of hypervitamonis $\mathrm{A}$ in the juvenile fish. The results in the present experiments also clearly showed how the timing of VA intake affected the risk of vertebrae defects that may also occur during the early ontogeny in other fish.

\section{Conclusion}

Malformation of flounder was induced by the exposure to excess dosage of VA during the G stage of larval development when notochord segmentation took place. The VA toxicity increased in more intense concentrations, resulting in a higher frequency of vertebral deformity, leading to a retardation of growth.

Acknowledgments The expenses of the present study were deprayed in part by a Grant in Aid for Scientific Research from the Ministry of Education, Science, Sport and Culture and by the Fisheries Agency, Ministry of Agriculture, Forestry and Fisheries.

\section{References}

1) T. Takeuchi, J. Dedi, C. Ebisawa, T. Watanabe, T. Seikai, K. Hosoya, and J. Nakazoe: The effect of $\beta$-carotene and vitamin A enriched Artemia nauplii on the malformation and color abnormality of larval Japanese flounder. Fisheries Sci., 61, 141-148 (1995).

2) J. Dedi, T. Takeuchi, T. Seikai, and T. Watanabe: Hypervitaminosis and safe levels of vitamin A for larval flounder Paralichthys olivaceus fed Artemia nauplii. Aquaculture, 133, 135-146 (1995).

3) E. F. Balart: Development of median and paired fin skeleton of Paralichthys olivaceus (Pleuronectiformes: Paralichthyidae). Japan. J. Ichthyology, 31, 398-410 (1985).

4) J. W. Hilton: Hypervitaminosis A in rainbow trout (Salmo gairdneri): Toxicity signs and maximum tolerable level. J. Nutr., 113, 1737-1745 (1983).

5) K. J. Rothman, L. L. Moore, M. R. Singer, U. D. T. Nguyen, S. Manino, and A. Milunsky: Teratogenicity of high vitamin A intake. New Eng. J. Med., 333, 1369-1373 (1995).

6) T. Watanabe, M. Ohta, C. Kitajima, and S. Fujita: Improvement of dietary value of brine shrimp Artemia salina for fish larvae by feeding them on $\omega-3$ highly unsaturated fatty acids. Nippon Suisan Gakkaishi, 48, 1775-1782 (1982).

7) T. Minami: The early life history of a flounder. Nippon Suisan Gakkaishi, 48, 1581-1588 (1982).

8) R. G. D. Steel and J. H. Torrie: Principles and Procedures of Statistics. A Biometrical Approach. McGraw-Hill Book Company Inc., New York, NY, 1980, 633p.

9) E. H. Park and D. S. Kim: A procedure for staining cartilage and bone of whole vertebrate larvae while rendering all other tissues transparent. Stain Technology, 59, 269-272 (1984).

10) K. Kawamura and K. Hosoya: A modified double staining technique for making a transparent fish-skeletal specimen. Bull. Natl. Res. Inst. Aquaculture, 20, 11-18 (1991).

11) J. Folch, M. Lee, and G. H. S. Stanley: A simple method for the isolation and purification of total lipids from animal tissues. J. Biol. Chem., 226, 497-507 (1957).

12) AOAC: Oils and fats. In: "Official Methods of Analysis, 14th edn." (ed. by S. Williams), AOAC Inc., Virginia, 1984, pp. 503532.

13) T. Takeuchi, K. Watanabe, W. T. Yong, and T. Watanabe; Essential fatty acids of grass carp Ctenopharyngodon idella. Nippon Suisan Gakkaishi, 57, 467-473 (1991).

14) P. Juaneda and G. Rocquelin: Rapid and convenient separation of phospholipid and non-phosphorus lipids from rat heart using silica cartridge. Lipids, 20, 40-41 (1985).

15) T. Watanabe and V. Kiron: Prospects in larval fish dietetics. Aquaculture, 124, 223-251 (1994).

16) DeW. S. Goodman, H. S. Huang, and T. Shiratori: Tissue distribution and metabolism of newly absorbed vitamin $A$ in the rat. $J$. Lipid Res., 6, 390-396 (1966).

17) N. H. Fidge, T. Shiratori, and J. Ganguly: Pathways of absorption 
of retinal and retinoic acid in the rat. J. Lipid Res., 9, 103-109 (1968).

18) Y. Muto and DeW. S. Goodman: Vitamin A transport in rat plasma. Isolation and characterization of retinol-binding protein. $J$. Biol. Chem., 247, 2533-2541 (1972).

19) A. K. Malia, J. E. Smith, and DeW. S. Goodman: Metabolism of retinol-binding protein and vitamin A during hypervitaminosis $\mathrm{A}$ in the rat. J. Lipid Res., 16, 180-187 (1975)

20) F. R. Smith and DeW. S. Goodman: Vitamin A transport in human vitamin A toxicity. New Eng. J. Med., 294, 805-808 (1976).

21) J. N. Hathcock, D. G. Hattan, M. Y. Yenkins, and J. T. McDonald: Evaluation of vitamin A toxicity. Am. J. Clin. Nutr., 52, 183-202 (1990).

22) S. Meghji: Bone remodelling. Br. Dent. J., 172, 235-242 (1992). 